\title{
THE VALUE OF RECORD KEEPING: A CASE STUDY FROM FOUR ELDERLY ORCHID ACCESSIONS
}

\author{
Andrea Fowler ${ }^{1}$
}

The history of four orchids growing at the Royal Botanic Garden Edinburgh (RBGE), some of the oldest accessions still in cultivation in the Indoor Department, is outlined. Records from the time of their arrival have been invaluable in providing an insight into the history of plant collecting, introduction and cultivation methods from the $1890 \mathrm{~s}$. They demonstrate the importance of accurate record keeping and the potential for species conservation in botanic gardens.

\section{INTRODUCTION}

The four oldest orchid accessions at RBGE date from 1896, the current specimens being vegetative propagules from the original plants acquired in that year (see the section on propagation below). Two of the species originated in Columbia, one from Guatemala and one from North East India. Recent interest in these old collections has stimulated research to trace their origin and document their history at RBGE.

These four species arrived at RBGE during the 'golden age' of plant hunting and orchid cultivation. Orchid prices peaked in 1906, after which time horticulture on the grand scale declined, especially with the advent of the First World War. During the early part of the twentieth century little attention was given to the natural environment of these plants and their conservation. Orchid collectors stripped whole areas of their plants to prevent competitors sharing their bounty. One description of a new Cattleya 'provisionally named gluckiana' proudly stated that 'every plant [from that locality] was collected'. Collectors for nurseries would sometimes deliberately give an incorrect origin in order to put rival collectors off the scent of a good site. To make matters worse, many of these orchids did not survive the journey back to Europe or died through incorrect cultivation methods in glasshouses. Today, botanic gardens and the horticulture industry are more responsible and, with the introduction of CITES and the Convention of Biological Diversity, endangered plants are generally safer. For botanic gardens in this age of conservation awareness plant records are invaluable. They show vitally important details of wild collected plants, and offer a fascinating insight into their history within a botanic garden such as Edinburgh.

In the RBGE archives there is a printed catalogue listing all the orchids growing in the Garden in March 1896, which shows a surprising total of more than 1260 orchid taxa, belonging to 110 genera. Three of the plants, Coelogyne holochila, Dracula bella and Stanhopea saccata were purchased from the Protheroe and Morris Auction House. Protheroe and Morris was probably the most famous horticultural auction house at the turn of the twentieth century during the height of 'Orchidmania'; a period analagous to the 'Victorian fern craze' when the fashion for a particular plant group reached extraordinary levels and

'Andrea Fowler is an Indoor Horticulturist at RBGE where she is responsible for the temperate orchid collection. Address: Royal Botanic Garden Edinburgh, 20a Inverleith Row, Edinburgh EH3 5LR. Email:a.fowler@rbge.org.uk 


\section{SALES BY AUCTION,}

MONDAY NEXT. IMPORTANT SALE OF BORDER PLANTS

$M^{R}$ J. O. STEVENS will SELI by

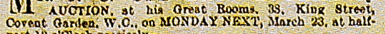

A GRAND COLLBOTION OF BORDER PLANTS RARE ROME-GROWN LILTUMS AXD BULBU OR A MFENTAL SHRURS FROM HOLLAND

STOV'S AND GRERNHOUSE PLANTS,

CLIMARR, JAPANESE LILIBS, ROSRS, so.
On viow morniog of Sale, and Catalogues had.

\section{WEDNESDAY NEXT.}

\section{LOTS OF ROSES AND SHRUBS.}

Several thousand cbolce nsnied
STANDARD, BALF-STANDARD, DWARF, OLMPINO, ROS E S

Frapo celebrated Eogliab, German, and Duteh Grower Standard, Pyramid, and Dwarl-traioed FRUTT TREES. JAPANESE LILIUSS

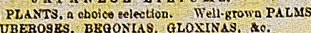

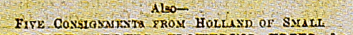
DECORATIVB SBRUBS. FLOTERING TREES, QCC. Nomprisiog-
Seress hundred AZALBA MOLLIS

the rariety of spall EVERROBRENS for

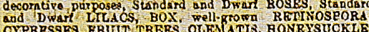
and oftaer Gimbers; LInTMSR, PAEONIES, DIANTHUS; spleadid order for presont plasting.

MR. J. C. STEVENS will SELL the above

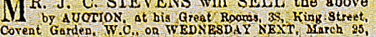

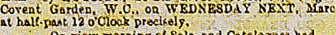

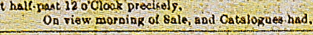

Thursday Next.
The somerhill Colleotion of Eatabilshed orchids. $M^{R}$. J. C. STEVENS has reoeived instrucMild tions trom the Executors of the inte Sir Julian Gold.

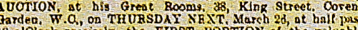

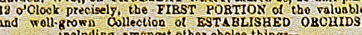

Cattlega Mossive Relacekiang Odontoglossum vexillorium " "e" Wagreri

Dë̈drochilunsts glumaceum
vallium
Disi Veitchii

Ylsa Veitubii
Yaode terest
Thuoia Veitchil

Leclis Gouldisas
Coulogyno Dayans
Anthariom Aodreanu

Aatbarlum Aodres

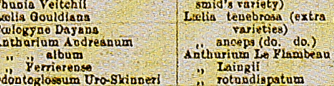

Od'oncoglossum Uro-Skineri

On viow morning of sole, Ao.

Taursday Noxt.

VALUABBLETARPORTED OROHID

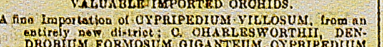

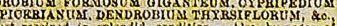

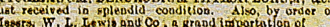
in. WNEL CATTLEYS WLRNERT

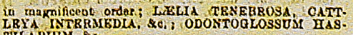
M R. J. C. STEVENS will inolude the above 38, King strect, Coreat Garden, of THULADAY RDXT: March 22.
On viar nuoring, or Sajo, and Gatalogucs bad. Tharsday Noxt.

C A T TLEYA SPECIES

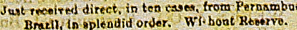

MR, J. $C$, SLEVENS Fill include the sbove in

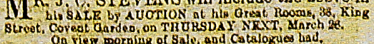

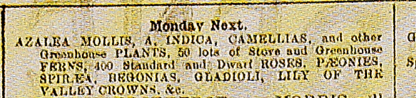
VALLEY CROWNS, Re.
MSSRS, PROTHEROE AND MORRIS will

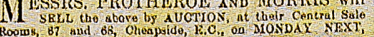

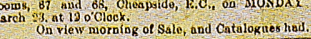
Tuosacy Next. March 24 .

By order of Nr. P. Sfotrthur, The London Nursories, MESSRS, PROTHATRROE AND MORRIS

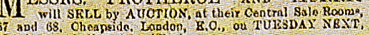

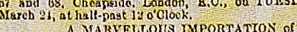

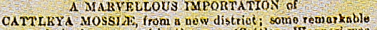

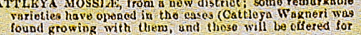

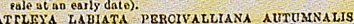
(TMUE).-Flowers in December; quite distinot from the

NEW GIGANTIO OATTLEIS, provisionally inmed

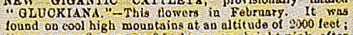

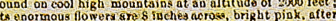

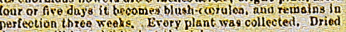
loirers will be exthitited at the Sale.

LIA GORTONI, new, rery woaderful. The Collector says

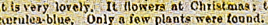

A Marsellous Importation of ANQULOA RUOKERII SU.

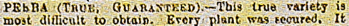
gives us greast pleasure in belog able to (ffer this uniquo varioty. IMURE LORUA, LYOASTE SOHIIERLANA, ANGULOA.

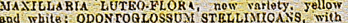
many other raluable imported planta.
On rier moraing of Sale, and Cataloznes had.

WEDNESDAY NEXT

220 CASES OF JAPAMESE LLLIES, \&C.

\section{ast received direct, in grand condition, com prisiog :-}

9.409 LILIUM AURATUAI. RUBRO. VITIATUM:

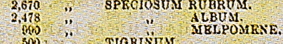

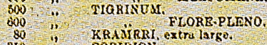

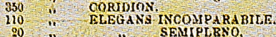

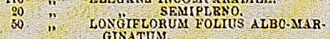

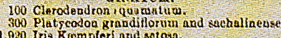

1.018 Pears.
sio Mraples.

810 Mraples.
160 Trec Pronies.
291 Dorallia builata.

1, 53 Poralimasos.
io 165 , Poly gooug sactalinense seed.

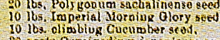

Alko and macratloum. DWARE PEARL TUBEKOSBS, 330 largo bulbs OAL
DIUM BSOULENTUM, GLADTOLUS LENOIS

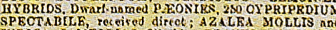

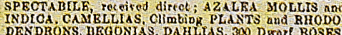

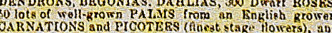
20,000 SEEDS PHGENIX ROPICOLA.
M ESSRS. PROTHEROE AND MORRIS will

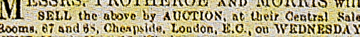

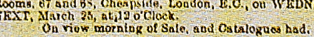

Tuoday. MTaros 31 .

Order of W. L. LSIFI \& OO, Sonthgate
SPRCIAL AND ISPORTANT SALR.

Grand Impottetions of

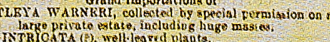

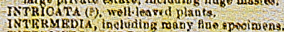

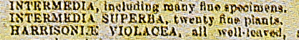

grand condition.
OITRINA, in quasitis.

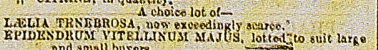

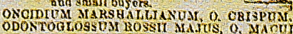

MESSRS. PROTHEROE AND MORRIS

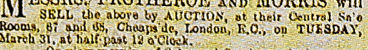

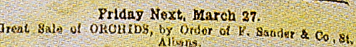

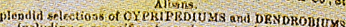

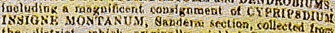

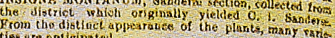

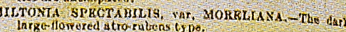
consignment of OY PRIPRBDLUAs seat by the Collector, is

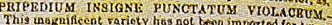

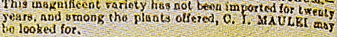

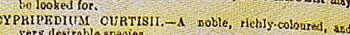
rert desirable oppesieo.

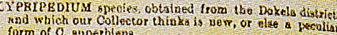

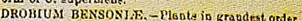
COZLOGXNB OCELLATA, MAXIMA. - A beaniflal, nesily

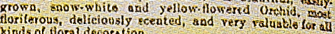
1000 Plants of VANDA CORULEA, gothered from tso distrits

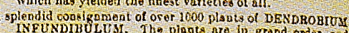
ive strongly recommend this opportuatity of aequirit

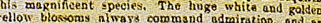
mots sersicesble for decoration. Also
UUNA BRNSONIS. DENDROBIUM CRASSINODB,

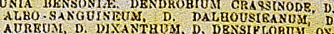

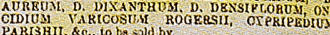
MESSRS. PROTHEROE AND MORRIS a M their Centril auction Booms, 67 and 69 , Clespald

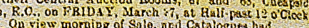

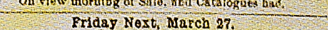
"REICHENBACBIA" - The grost work on Orehils, thlo

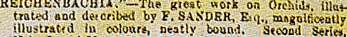
Vols, I. and It. JAMES BATESAN, ESy.
MESSRS, PROTHEROE AND MIORRIS will II ESSRS. PROTHEROE AND MIORRIS will ERIDAY NRAT, Manob 27, a: $20^{\circ}$ clock. By Order of

Mr. P. Mc Arthur, THE LONDON NURSERIES, 4, MAIDA VALE, W,

MESSRS. PROTHEROE \& MORRIS

Will Sell at their Sentral Auction Rooms, 67 \& 68 , Cheapside, E.C.,

A MAGNITIOENT IMPORTATION OF

NEW ORCHIDS,

With many rare rarieties of ODONToglassusis, snd a splendid lot of the true

ANGULOA RUCKERI SUPERBA On vievo morning of Sale, anl Catalogues hedd. FRIDAX, MARCH 27, 1898.

\section{DER is C0, Sr. Armuss.}

\section{GREAT SALE OF ORCHIDS.}

1000 VANDA CORULE

1000 DENDROBLUA TNEUNDRBULUA. CYPRIPEDIUN INSIGNE MONTANUM OIPRIPEDIUN INSTGNE PUNOTATUM MILTONIA MORELIANA.

COLLOQXNE OCELLATA MAXIVA.

CXPRIPEDIUN CURTISII

And splendid salections of the nost besutiful
DENDROBES in great variety, it old ding TO $B E$ SOLD BY

MESSRS, PROTHEROE \& MORRIS,

67 \& 68, CHMADSIDE, E.C.

On FRIDAY, MARCA 27, 1898,

Plate 1. Gardener's Chronicle January-June 1896 p350 showing advertisments for up and coming auctions. 


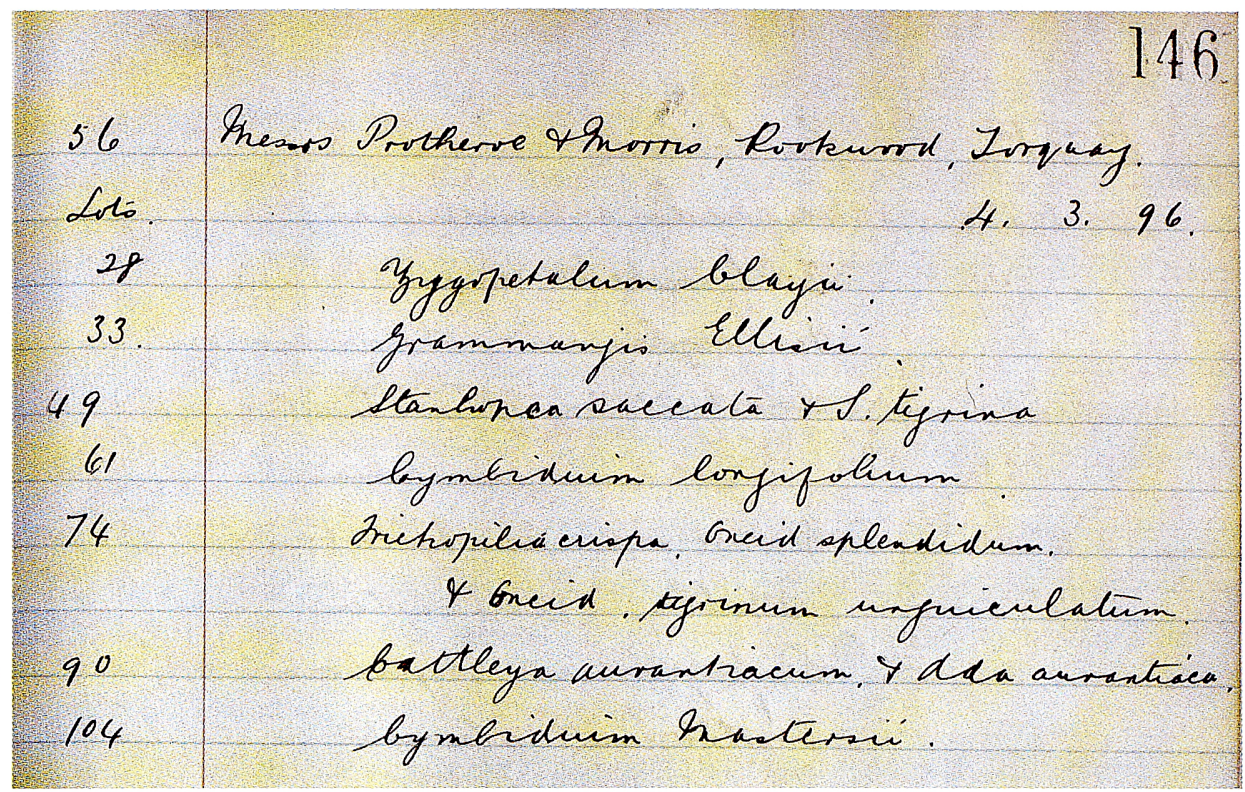

Plate 2. Page from RBGE accession book 1896. The auction lot numbers are written in the left hand column.

enthusiasts were prepared to pay huge prices for plants they craved and were prepared to dig up vast numbers from the wild. Located at Cheapside, London it was very close to the stock exchange, which provided a potential source of wealthy customers. William Henry Protheroe (1846-99) and George Field Morris (1831-1909) were both members of the RHS Orchid Committee. A page from the classified section of the Gardener's Chronicle for March 1896 (Plate 1) is filled with notices for forthcoming auctions and sales; these included advertisements for a number of lilies, roses and shrubs in addition to orchids, and gives an idea of the scale of these commercial activities. The firm of Protheroe and Morris features prominently, but other auction houses, private collections and nurseries are also advertised.

The sheer number of wild collected plants and seeds that they sold are unimaginable in these conservation-minded days. The following lots for instance were sold at individual sales in 1896: 270,000 Kentia forsteriana seeds, 59,000 Lillium harrisii, 3,000 Odontoglossum alexandrae and 2,000 Cattleya aurantica. It should be noted that the orchids were not all taken directly from the wild. Protheroe and Morris also sold orchids obtained from famous orchid nurseries such as Sanders of St. Albans (after which Paphiopedilum sanderianum is named). Private collections were also auctioned by Protheroe and Morris, but whether this was because the owners had died or their passion for orchids faded was not recorded.

The RBGE accession books dating from the time are a valuable source of information (Plate 2). The date that each plant arrived at the Garden and its source were written by hand into large ledgers. These are now stored in the Plant Records Office at RBGE and serve as a reminder of the past, when records were far less detailed than those held on the present BG-BASE database. 
THE PLANTS

Examining the accession books we find the following details:

Coelogyne holochila Hunt \& Summerhayes, native to NE India. Arrived as C. alata on 21 February 1896 from Protheroe \& Morris. It was subsequently named C. stricta before receiving what is currently believed to be its correct name.

Stanhopea saccata Bateman, native to Guatemala. Arrived in a batch of 11 species of orchid purchased on 4 March 1896 from Protheroe \& Morris, and which originally came from the collection of Rockwood House, Torquay.

Dracula bella (Reichenbach) Luer, native to Columbia. Arrived as Masdevallia carderi on 27 March 1896 purchased from Protheroe \& Morris. This was among a collection of one hundred species of orchid, including 79 species of Masdevallia. Dracula was separated from the genus Masdevallia by the botanist A. Luer Carlyle in 1978.

Maxillaria turneri Nichols, native to Columbia. Donated to RBGE by Dr J. Foulis (1846-1901) of 34 Heriot Row, Edinburgh on 10 July 1896. This was among a collection of 25 orchids, but individual species were not listed. Less than one month later another batch of 480 Orchids arrived from Dr Foulis, in what we can only presume to be another generous gift.

The accession books show that in one month alone, March 1896, RBGE bought or was given more than 334 orchid taxa. Many of the prices are recorded in the accession books, and the total spent in this month would amount to the equivalent of $£ 4417$ in today's terms. The most expensive plant was a Cattleya mossiae (Low’s Strain) at twenty shillings (£1). In contrast, others were very cheap: a collection of Cypripedium and Paphiopedilum was bought, with prices ranging from eight pence ( $3 p)$ to fifteen shillings $(75 p)$ per plant.

\section{CULTIVATION OF ORCHIDS AT RBGE}

At present there are around 1500 orchids in the collection of the Indoor Department at RBGE representing 159 genera and 849 taxa. These are grown in the Orchid and Cycad display glasshouse, and in the temperate and tropical 'back-up' glasshouses where plants are cared for when not on public display. The Orchid and Cycad house and the tropical back-up house are heated to a night minimum temperature of $18^{\circ} \mathrm{C}$ and a daytime maximum of $26^{\circ} \mathrm{C}$. The temperate back-up house has a night minimum temperature of $11^{\circ} \mathrm{C}$ and a daytime maximum of $17^{\circ} \mathrm{C}$. Automatic vents open when these maxima are reached on hot days. Heating is provided by gas-fuelled medium pressure hot water pipes. Air circulation fans keep the atmosphere buoyant in the winter and reduce the temperature in summer. Since their installation in early 2004 these fans have been very effective in reducing bacterial spotting and generally improving the health of the plants. Shading is provided internally by light reflective $50 \%$ shading material in the summer months. 
All four of the species discussed above are epiphytes and as such are potted in an epiphytic orchid mix comprising coarse orchid grade bark, perlite and charcoal. Nutrients are provided throughout the growing season using water-soluble feeds weekly at a quarter to a half of the manufacturer's recommended quantities. The concentration used is dependent on the genus and size of plant. During the growing season a high nitrogen feed is used, which is replaced with a high potash feed at the end of the growing season. It is important to water between liquid feeds to flush out any build up of salts in the compost. Water comes from the mains supply which has a $\mathrm{pH}$ of 7.5 and does not leave a chalky deposit on the foliage of the plants.

In the tropical glasshouse Stanhopea saccata is grown in a slatted hanging basket. The flower stalk often penetrates the open compost and appears on the underside of the basket. Coelogyne holochila, being a large plant, is grown in a pot for ease of cultivation. Maxillaria turneri and Dracula bella are grown in the temperate glasshouse. As a clump forming herb Maxillaria turneri is best suited to pot culture. Dracula bella is cultivated in a moss lined basket, and as its native environment is the cloud forest of Columbia, it requires high humidity and cool temperatures.

Propagation is always by division at RBGE. At least three pseudobulbs and a growth are separated from the main plant in spring. These are then potted on and cultivated in the normal way.

It should be noted that orchid cultivation techniques were rather different when the plants arrived in the nineteenth century and it seems worth giving a note here on changes in growth media used during the intervening period. In 1896 the orchids were probably

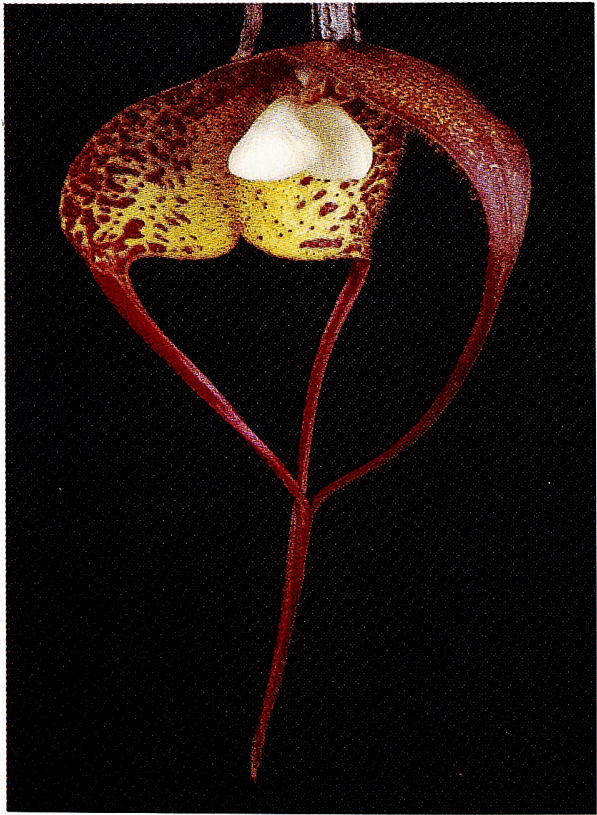

Plate 3. Dracula bella photographed in March 2005 at RBGE.

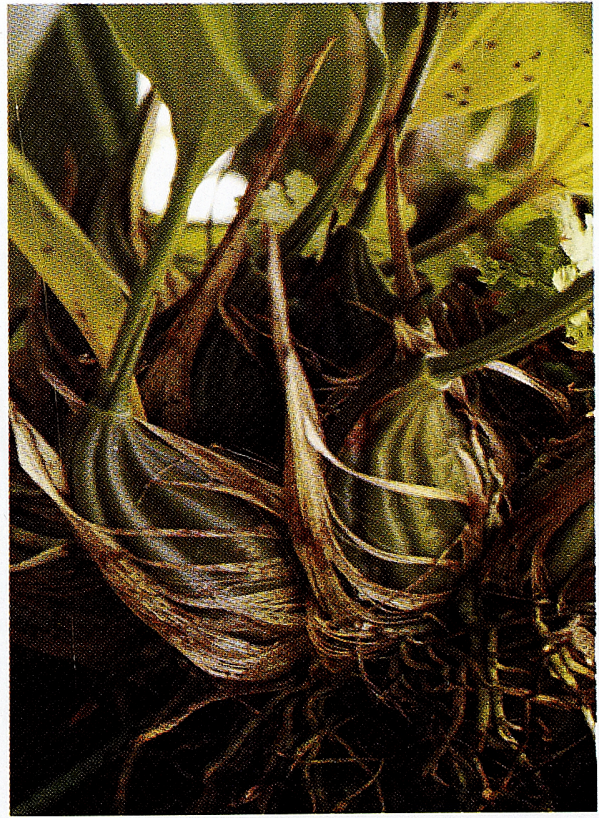

Plate 4. Orchid pseudobulbs suitable for propagation 
grown in terracotta pots with degraded fibre of the royal fern (Osmunda regalis) or coarse peat, which were then the preferred orchid growing medium. Royal fern fibre imported from Japan was still in use at RBGE as recently as the mid 1970s. It arrived in large bales which required chopping. When conservation concerns were raised the price rose, and 'impostor' substances, which provided a substandard growing medium, began to arrive. Other alternatives, such as coconut fibre were tried but proved not suitable for all species. The milled pine bark, which is currently used, became the most economical and successful growth medium during the 1980s (Alistair Paxton, pers. comm.) Sphagnum moss was also in use in 1896 as reported by H.A. Burberry of Highbury, Moor Green, Birmingham:

"Masdevallias may also be repotted now...Peat and sphagnum moss in equal proportions suits them best. See that they are made quite steady and water very carefully for a time." (Burberry, 1896).

\section{REFERENCE}

BURBERRY, H.A. (1896). Calendar of operations for January. Orchid Review 4: 24-29. 